\title{
Intraoperative fluorescence with indocyanine green in congenital cardiac surgery: Potential applications of a novel technology
}

Sameh M. Said, MBBCh, MD, FACS, ${ }^{\mathrm{a}, \mathrm{b}}$ Gamal Marey, MD, ${ }^{\mathrm{a}}$ and Gurumurthy Hiremath, MD, FACC ${ }^{\mathrm{c}}$

\section{ABSTRACT}

Background: Achieving successful repair of congenital heart defects requires attention to detail. Careful evaluation of anastomotic site patency, reimplanted coronary arteries, location of epicardial coronaries, and myocardial perfusion may be necessary to ensure safe conduct of the operation and achieve excellent outcomes.

Methods: Intraoperative fluorescence angiography (IOFA) was performed using indocyanine green in patients undergoing the following procedures: coronary artery reimplantation, coronary artery unroofing, evaluation of intraoperative coronary anatomy, reoperation requiring ventriculotomy, coarctation/interrupted aortic arch repair, systemic-to-pulmonary artery shunt, Norwood procedure, thoracic duct localization, and vascular rings.

Results: The technique was feasible in all patients. No mortality or adverse events related to the dye were encountered. Adequate intraoperative imaging was obtained in 15 patients (20 images), which correlated well with postoperative studies. The imaging quality was superior for assessing shunt patency, myocardial perfusion, and anastomotic patency and determining the location of epicardial coronary arteries but was less so for assessing branch pulmonary arteries.

Conclusions: IOFA is a useful and safe technique that can provide a quick on-table assessment of a variety of congenital surgical procedures. This may help answer questions that can minimize postoperative interventions and help ensure a smooth perioperative course and excellent outcomes. (JTCVS Techniques 2021;8:144-55)

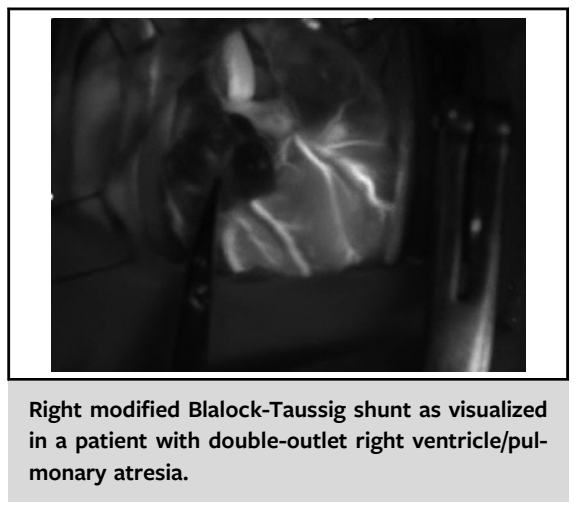

CENTRAL MESSAGE

Intraoperative fluorescence

angiography is a useful technique

that can provide quick answers

to many intraoperative ques-

tions. This may facilitate the

perioperative course and help

achieve satisfactory outcomes. PERSPECTIVE
Indocyanine green has been used for intraopera-
tive fluorescence angiography in a variety of sub-
specialties, but its role in pediatric cardiac surgery
is unclear. The technology is available and safe,
and it may have the potential for various applica-
tions. It provides a quick tool to answer many in-
traoperative questions and help ensure safe
conduct of the operation and a smooth perioper-
ative course.

See Commentaries on pages 156 and 158.
From the Divisions of ${ }^{\mathrm{a}}$ Pediatric Cardiovascular Surgery and ${ }^{\mathrm{c}}$ Pediatric Cardiology, Masonic Children's Hospital, University of Minnesota, Minneapolis, Minn; and ${ }^{\mathrm{b}}$ Faculty of Medicine, Alexandria University, Alexandria, Egypt.

Received for publication Feb 5, 2021; accepted for publication Feb 19, 2021; available ahead of print February 25, 2021.

Address for reprints: Sameh M. Said, MBBCh, MD, FACS, Division of Pediatric Cardiovascular Surgery, Masonic Children's Hospital, University of Minnesota, 2450
Riverside Ave S, East Building, MB 539, Minneapolis, MN 55454 (E-mail: ssaid@ umn.edu). 2666-2507

Copyright (C) 2021 The Authors. Published by Elsevier Inc. on behalf of The American Association for Thoracic Surgery. This is an open access article under the CC BY-NCND license (http://creativecommons.org/licenses/by-nc-nd/4.0/). https://doi.org/10.1016/j.xjtc.2021.02.026 


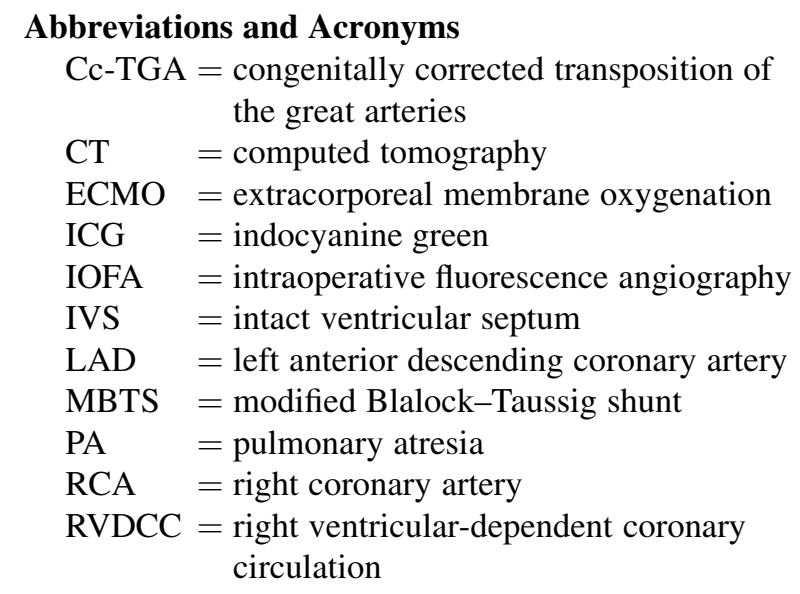

Video clip is available online.

In the current era, the expectations are high regarding outcomes after repair of congenital heart defects regardless of the complexity. In many operative scenarios, the surgeon may find himself or herself in a tricky situation that requires careful assessment of the procedure that was performed, and if there is a safety concern, it becomes prudent to have a backup plan.

Intraoperative fluorescence angiography (IOFA) using indocyanine green (ICG) has emerged as an easy and safe technique that can be performed in the operating room to evaluate the quality of anastomoses in coronary artery bypass surgery. ${ }^{1}$ ICG is a hydrophilic tricarbocyanine dye that rapidly binds to plasma proteins and is excreted in bile. When ICG is exposed to near-infrared rays, it generates fluorescence. ${ }^{2}$ IOFA has been widely used in other specialties, including ophthalmology, ${ }^{3}$ gastrointestinal surgery, ${ }^{4}$ and sentinel node mapping in breast cancer ${ }^{5}$; however, application of this technology has been quite limited in cardiac surgery in general and in congenital cardiac surgery in particular. Here we present our experience using this technology.

\section{METHODS}

\section{Properties of ICG}

ICG as an imaging agent has a short half-life and a long history of safe use. It generates fluorescence with a wavelength of 800 to $850 \mathrm{~nm}$ when exposed to a 760 to $780 \mathrm{~nm}$ wavelength of near-infrared rays. ${ }^{6}$ The amplitude of its fluorescence is highest at a concentration of $2.5 \times 10^{-3} \mathrm{mg} / \mathrm{mL}^{7}$ ICG has been used in a wide variety of specialties including ophthalmology, ${ }^{8}$ sentinel lymph node mapping in oncologic surgery, ${ }^{9}$ gastrointestinal surgery, ${ }^{10}$ and cardiovascular surgery. ${ }^{11}$

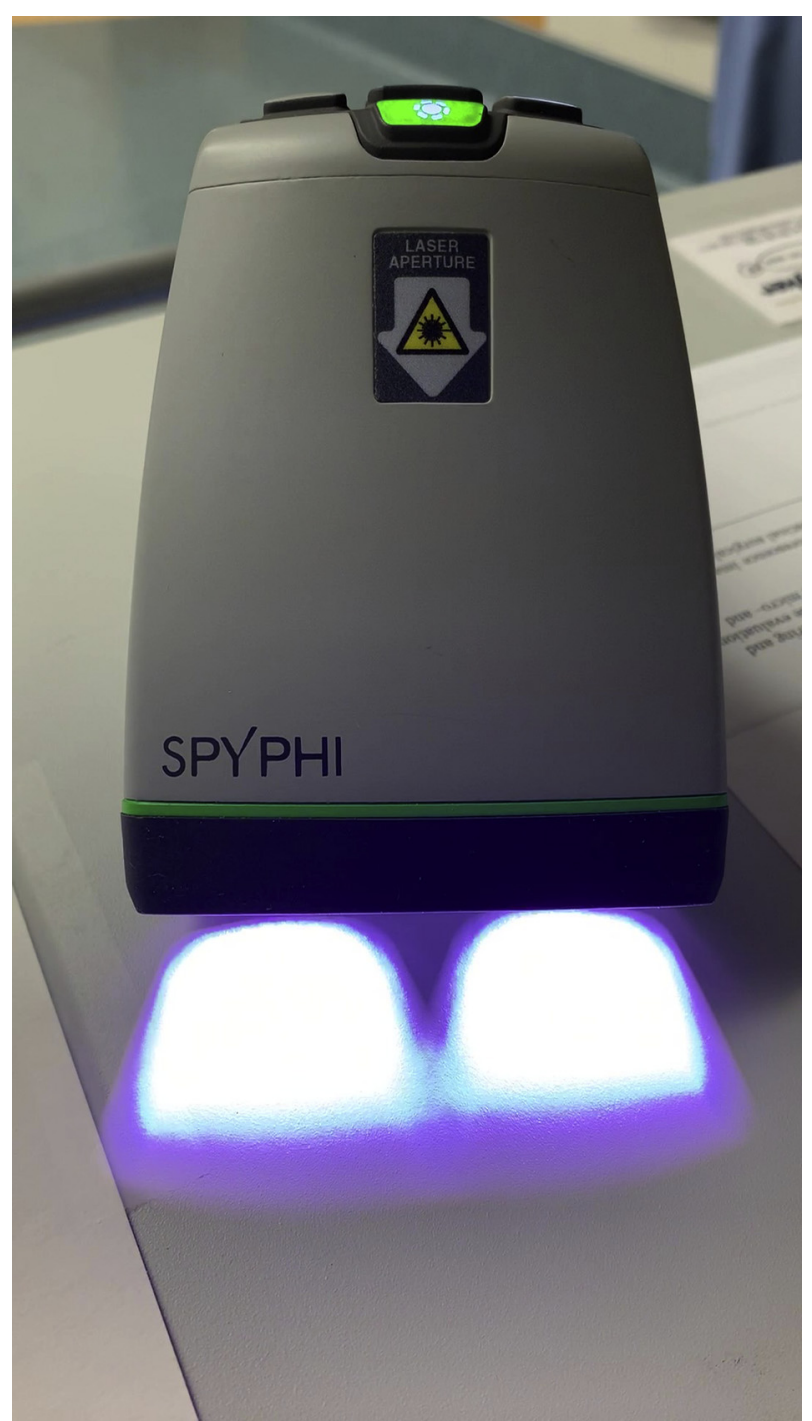

VIDEO 1. A handheld probe via a sterile sleeve is used for image acquisition intraoperatively. It emits infrared rays, which excites indocyanine green fluorescence. Video available at: https://www.jtcvs.org/article/ S2666-2507(21)00178-4/fulltext.

\section{IOFA System}

A commercially available IOFA system (SPY-PHI; Novadaq Technologies, Toronto, Canada) was used in this study. The use of an infrared probe facilitated the generation of real-time images (Video 1). Components included a handheld imaging probe (Figure 1, $A$ ), a video processor/illuminator (Figure 1, $B$ ), and a monitoring screen on which the surgeon is able to visualize the acquired images.

\section{Pediatric Dosage}

There is no fixed dose. The vial of ICG (SPY AGENT GREEN) contains $25 \mathrm{mg}$ of ICG. The standard dilution is for 1 vial reconstituted with $10 \mathrm{~mL}$ of sterile water $(2.5 \mathrm{mg} / \mathrm{mL})$. The ICG dose is weight-based (Figure 1,C), from the dilute ICG solution. We used several dilution strategies (Table 1), 


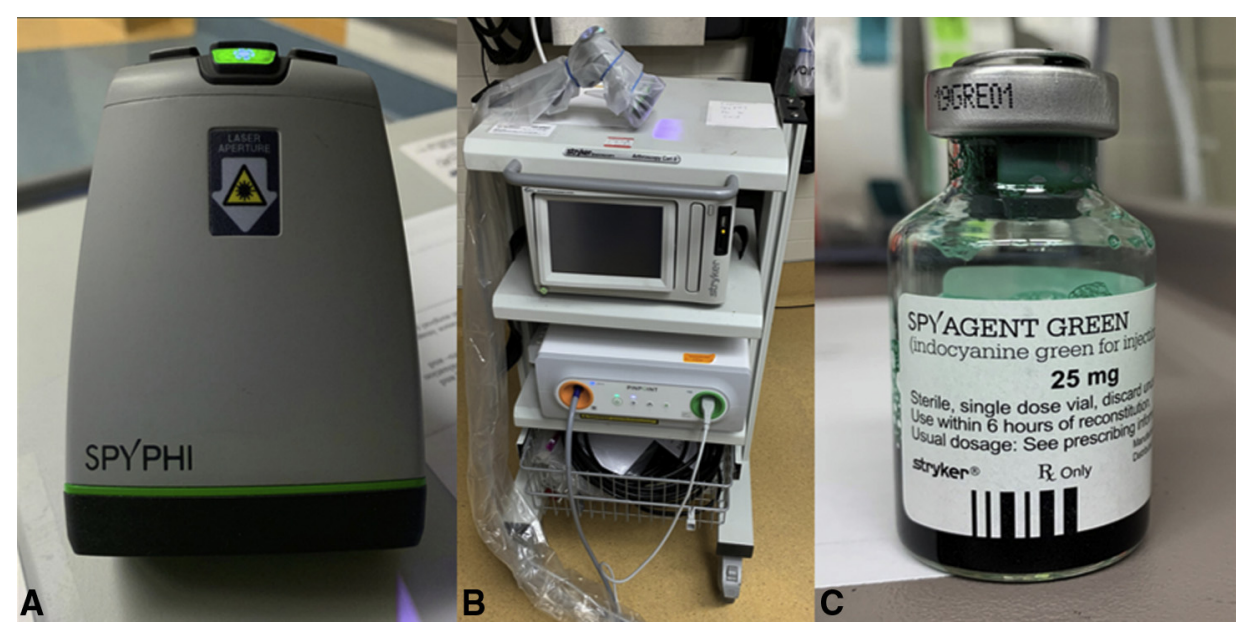

FIGURE 1. Multiple components are needed for proper image acquisition. A, Hand-held near-infrared imaging probe. B, Video processor/illuminator (VPI) unit. C, Indocyanine green (SPY AGENT GREEN) comes in 25-mg vials.

with the goal of obtaining the best possible images with the smallest ICG dose and the least volume.

We started with an ICG concentration of $0.013 \mathrm{mg} / \mathrm{mL}$, with the aim of finding the lowest effective concentration; however, the images were faint, and a larger volume of the contrast was needed. Thus, we switched to a concentration of $0.28 \mathrm{mg} / \mathrm{mL}$ for arrested heart cases and $0.5 \mathrm{mg} / \mathrm{mL}$ for all other cases. We believe that $0.5 \mathrm{mg} / \mathrm{mL}$ is the optimal concentration necessary to provide good quality images with the least volume of diluted ICG. This was used in a total volume of $1 \mathrm{~mL}$ in neonates and infants weighing $<8 \mathrm{~kg}$ and $2 \mathrm{~mL}$ in those weighing $>8 \mathrm{~kg}$. In the 2 older patients, weighing $45 \mathrm{~kg}$ and $80 \mathrm{~kg}$, we used up to $3 \mathrm{~mL}$ of volume (Table 2).

We drew the dilute ICG in a 3-mL syringe and administered it in a "burst fashion" dose after dose, not exceeding the maximum allowed $(2 \mathrm{mg} / \mathrm{kg})$. We never reached close to the maximum dose in any of the current cases, but we most often performed repeated injections, always starting with a smaller dose. A hypodermic needle was used to perform the injection directly into the aortic root/proximal to the constructed shunt/anastomosis. (beating heart with or without cardiopulmonary bypass).
We learned from clinical experience to modify the concentration of the ICG based on the technique of injection, and the dose with a beating heart is further diluted compared with the dose with an arrested heart. This is important to avoid oversaturation of the image, which will obscure the fine details.

\section{Technique}

The Institutional Review Board at the University of Minnesota approved this study (no. 00011157; date of approval, 10/12/2020), and the need for consent was waived due to the study's retrospective nature. Baseline imaging was obtained before initiation and then after weaning off cardiopulmonary bypass. There are 3 display modes: overlay mode, in which the fluorescence image (green) is displayed over a white light image (Figure 2, A); SPY CSF mode, in which a white light image is displayed in grayscale with fluorescence overlaid in a color scale (Figure 2, B); and SPY mode, the mode that we used, in which a fluorescence image is displayed in grayscale (Figure 2, C). A sterile sleeve is used to allow use of

TABLE 1. Different dilution strategies for ICG and potential applications

\begin{tabular}{|c|c|c|c|}
\hline Dilution & Reconstitution & $\begin{array}{l}\text { Final concentration, } \\
\mathrm{mg} / \mathrm{mL}\end{array}$ & Application \\
\hline Standard & $\begin{array}{l}\text { Reconstitute a } 25-\mathrm{mg} \text { vial of ICG with } 10 \mathrm{~mL} \text { of } \\
\text { sterile water for injection. }\end{array}$ & 2.5 & Was not used in the present study. \\
\hline Very diluted & $\begin{array}{l}\text { Reconstitute a } 25-\mathrm{mg} \text { vial of ICG with } 10 \mathrm{~mL} \text { of } \\
\text { sterile water for injection. } \\
\text { Extract } 0.25 \mathrm{~mL} \text { of reconstituted ICG standard } \\
\text { dilution }(2.5 \mathrm{mg} / \mathrm{mL}) \text {, mix with } 48 \mathrm{~mL} \text { of normal } \\
\text { saline. }\end{array}$ & 0.013 & $\begin{array}{l}\text { Was used in the initial phase but it was } \\
\text { found to be very diluted with less-than- } \\
\text { optimal imaging quality and requires a } \\
\text { relatively large volume of contrast. }\end{array}$ \\
\hline Moderate dilution & $\begin{array}{l}\text { Reconstitute a } 25-\mathrm{mg} \text { vial of ICG with } 10 \mathrm{~mL} \text { of } \\
\text { sterile water for injection. } \\
\text { Extract } 1 \mathrm{~mL} \text { of reconstituted ICG standard dilution } \\
(2.5 \mathrm{mg} / \mathrm{mL}) \text {, mix with } 8 \mathrm{~mL} \text { of normal saline. }\end{array}$ & 0.28 & $\begin{array}{l}\text { We use it mostly after cardioplegic arrest, } \\
\text { where it is administered through the } \\
\text { cardioplegia line through a 3-way stopcock. }\end{array}$ \\
\hline Mild dilution & $\begin{array}{l}\text { Reconstitute a } 25-\mathrm{mg} \text { vial of ICG/SPY AGENT } \\
\text { GREEN with } 10 \mathrm{~mL} \text { of sterile water for injection. } \\
\text { Extract } 2 \mathrm{~mL} \text { of reconstituted ICG standard dilution } \\
(2.5 \mathrm{mg} / \mathrm{mL}) \text {, mix with } 8 \mathrm{~mL} \text { of normal saline. }\end{array}$ & 0.5 & $\begin{array}{l}\text { Our standard dilution method for all off-pump } \\
\text { and on-pump beating heart cases }\end{array}$ \\
\hline
\end{tabular}

ICG, Indocyanine green. 
TABLE 2. Patient characteristics and different intraoperative IOFA applications

\begin{tabular}{|c|c|c|c|c|c|}
\hline No & Age/sex & Weight, kg & Preoperative diagnosis & Procedure & IOFA indications \\
\hline 1 & $5 \mathrm{~d} / \mathrm{M}$ & 3.2 & DORV/PA; AV discordance & PDA ligation and right MBTS & MBTS shunt patency \\
\hline 2 & $10 \mathrm{mo} / \mathrm{F}$ & 8.4 & Branch PA stenoses & PA plasty (hilum to hilum) & Assess PA reconstruction \\
\hline 3 & $3 \mathrm{wk} / \mathrm{F}$ & 3.3 & Chylothorax, postcoarctation repair & Right thoracotomy/thoracic duct ligation & Thoracic duct localization \\
\hline 4 & $9 \mathrm{y} / \mathrm{M}$ & 45 & Vascular ring (RAA/ALSCA/KD) & $\begin{array}{l}\text { Left thoracotomy/resection of KD and } \\
\text { translocation of LSCA to LCC }\end{array}$ & LSCA/LCC anastomosis \\
\hline 5 & $8 \mathrm{~d} / \mathrm{M}$ & 4.3 & IAA with VSD and Cc-TGA & Repair of IAA and PAB & $\begin{array}{l}\text { Arch anastomosis; coronary } \\
\text { anatomy }\end{array}$ \\
\hline 6 & $2 \mathrm{~d} / \mathrm{F}$ & 3.5 & $\begin{array}{l}\text { TAPVC/AVSD/PA and } \\
\text { MAPCAs; heterotaxy }\end{array}$ & $\begin{array}{l}\text { Repair of TAPVC, ligation of MAPCAs } \\
\text { and aortopulmonary shunt }\end{array}$ & Central shunt (A-P) patency \\
\hline 7 & $7 \mathrm{~d} / \mathrm{F}$ & 2.6 & PA/IVS with RVDCC & $\begin{array}{l}\text { Double shunts (aorto-right ventricular } \\
\text { and right MBTS) }\end{array}$ & $\begin{array}{l}\text { Visualization of RVDCC; } \\
\text { aorto-TV-RV shunt; } \\
\text { right MBTS shunt }\end{array}$ \\
\hline 8 & $6 \mathrm{~d} / \mathrm{M}$ & 3.9 & HLHS (AA/MA) & Norwood/Sano & Myocardial perfusion \\
\hline 9 & $8 \mathrm{mo} / \mathrm{M}$ & 8.3 & DORV/VSD/PA; previous right MBTS & Takedown MBTS, 2-ventricle repair & $\begin{array}{l}\text { Visualization of MBTS; } \\
\text { determination of site for } \\
\text { safe ventriculotomy }\end{array}$ \\
\hline 10 & $10 \mathrm{mo} / \mathrm{M}$ & 7.7 & Cardiac arrest/LV thrombus & ECMO/LV thrombectomy & $\begin{array}{l}\text { Evaluation of coronary } \\
\text { arteries/myocardial } \\
\text { perfusion; detect } \\
\text { anomalous LAD origin } \\
\text { from RCA }\end{array}$ \\
\hline 11 & $15 \mathrm{y} / \mathrm{M}$ & 80 & HOCM/LAD myocardial bridge & Septal myectomy/LAD unroofing & Localization of LAD bridge \\
\hline 12 & $5 \mathrm{wk} / \mathrm{F}$ & 3.5 & PV stenosis/PA hypoplasia/cyanosis & Sutureless repair/Sano shunt & Sano shunt assessment \\
\hline 13 & $6 \mathrm{~d} / \mathrm{F}$ & 3.8 & Coarctation/VSD & One-stage repair & Aortic arch assessment \\
\hline 14 & $10 \mathrm{~d} / \mathrm{M}$ & 5.4 & TGA & Arterial switch & Myocardial perfusion \\
\hline 15 & $2 \mathrm{mo} / \mathrm{M}$ & 5.1 & TGA/VSD/bicuspid PV; previous PAB & Ross/switch & Myocardial perfusion \\
\hline
\end{tabular}

IOFA, Intraoperative fluorescence angiography; $D O R V$, double-outlet right ventricle; $P A$, pulmonary atresia; $A V$, atrioventricular; $P D A$, patent ductus arteriosus; $M B T S$, modified Blalock-Taussig shunt; $R A A$, right atrial appendage; $A L S C A$, aberrant left subclavian artery; $K D$, Kommerell's diverticulum; $L S C A$, left subclavian artery; $L C C$, left common carotid; $I A A$, interrupted aortic arch; VSD, ventricular septal defect; $C c-T G A$, congenitally corrected transposition of the great arteries; $P A B$, pulmonary artery banding; TAPVC, total anomalous pulmonary venous connection; $A V S D$, atrioventricular septal defect; $M A P C A$, major aortopulmonary collateral artery; $A-P$, aortopulmonary; IVS, intact ventricular septum; $R V D C C$, right ventricular-dependent coronary circulation; $T V$, tricuspid valve; $R V$, right ventricular; $H L H S$, hyposplastic left heart syndrome; $L V$, left ventricular; $E C M O$, extracorporeal membrane oxygenation; HOCM, hypertrophic obstructive cardiomyopathy; $L A D$, left anterior descending artery; RCA, right coronary artery; $T G A$, transposition of the great arteries; $P V$, pulmonary valve.

the probe in the operative field. Image recording is started before administration of ICG, owing to its short half-life.

ICG can be administered in various ways depending on the goal of the study. For coronary evaluation, ICG can be given by direct injection in the aortic root with a beating heart before initiation of cardiopulmonary bypass or through a cardioplegia cannula with a beating heart or an arrested/crossclamped heart. We usually connect a 3 -mL syringe to the aortic root cardioplegia needle via a 3-way stopcock and perform the injection that way. On an arrested heart after cardioplegia, the cardioplegia line must be primed with ICG. Once cardioplegic arrest is achieved, ICG is rapidly administered, which is sufficient to visualize the coronary arteries immediately.

For shunt assessment, ICG can be injected directly in the vessel proximal to the shunt anastomosis, for example, the aorta in a central shunt, the innominate artery/aorta in a modified Blalock-Taussig shunt (MBTS), and in the right ventricle in a Sano shunt.

For assessment of vascular anastomosis/reconstruction, ICG can be injected directly into the proximal vessel. For thoracic duct localization, ICG can be injected subcutaneously in both groins (with the dose divided equally) 20 to 30 minutes before a right thoracotomy.

An important point is to differentiate between technical problems in the anastomosis/shunt and inadequate ICG dosage, both of which can lead to inadequate visualization of the anastomosis/shunt. In these cases, we recommend repeating the dosage to avoid misleading the surgeon, which could result in unnecessary revisions/interventions.

Images were reviewed to determine their adequacy. Intraoperative images were correlated with intraoperative echocardiographic images as well as postoperative imaging studies. The intraoperative plan did not change based on the images obtained. Patients were followed postoperatively to detect any adverse events that possibly could be related to the technique.

\section{Clinical Applications}

In this study, the SPY-PHI system was used for intraoperative assessment and planning in 15 consecutive pediatric patients (mean age, 21 months; range, 2 days to 15 years; mean weight, $12.5 \pm 21.41 \mathrm{~kg}$ ) with a variety of diagnoses (Table 2). The procedures and image acquisition were performed by one surgeon (S.M.S.). Twenty images were obtained that facilitated the following assessments: systemic-to-pulmonary artery shunts patency $(n=6)$, coronary artery evaluation $(n=6)$, patency of vascular anastomoses/reconstructions $(n=4)$, myocardial perfusion $(\mathrm{n}=3)$, and thoracic duct localization $(\mathrm{n}=1)$.

Assessment of systemic-to-pulmonary artery shunts. All shunts were performed using cryopreserved saphenous vein homografts 


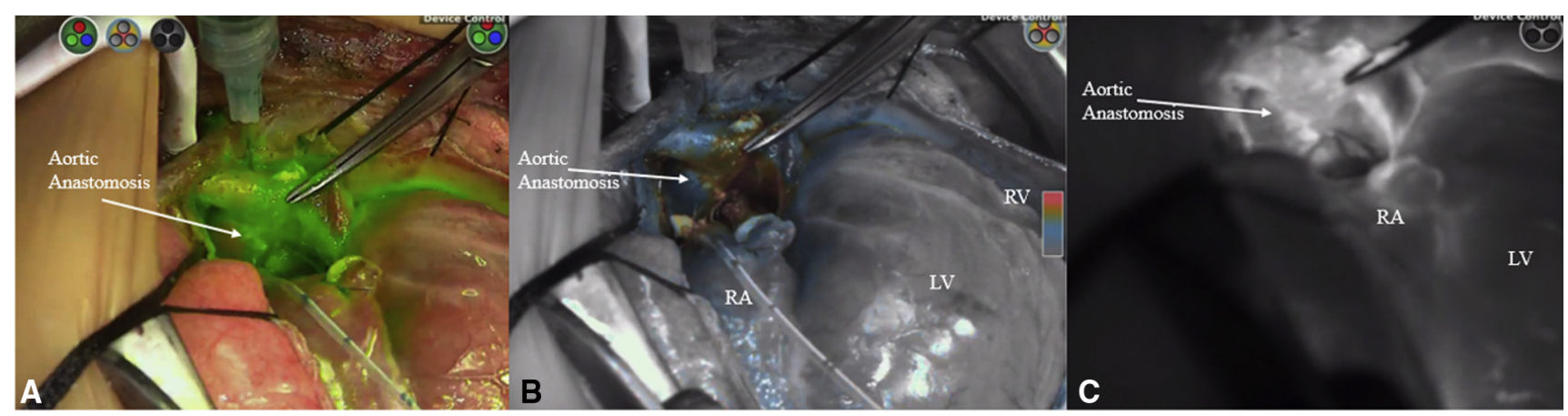

FIGURE 2. There are 3 display modes: A, Overlay mode, with the fluorescence image (green) displayed over a white light image; B, SPY CSF mode, in which a white light image is displayed in grayscale with fluorescence overlaid in a color scale; and C, SPY mode, in which the fluorescence image is displayed in a grayscale; this is the mode we have used. $R A$, Right atrium; $L V$, left ventricle; $R V$, right ventricle.

(without cardiopulmonary bypass in 2 neonates). These included a right MBTS in 3 neonates (Figure 3, $A$ and $B$ ), a central aortopulmonary shunt in 1 neonate (Figure 4), and a right ventricular-to-pulmonary artery shunt (Sano) in 1 neonate (Video 2). In an usual case of pulmonary atresia with an intact ventricular septum (PA/IVS) and right ventricular-dependent coronary circulation (RVDCC), a shunt was placed between the ascending aorta and the right ventricle through the tricuspid valve to augment coronary arterial flow (Video 3).

Evaluation of coronary arteries. We used ICG/IOFA to determine the location of epicardial coronary arteries in 1 patient who required right ventriculotomy (Figure 5, $A$ to $D$ ), to localize a deep left anterior descending (LAD) coronary artery myocardial bridge in another patient, and to evaluate a right ventricular-to-epicardial coronary arterial fistulae in a neonate with PA/IVS and RVDCC (Figure 6, $A$ and $B$ ). Coronary anatomy was also confirmed in a neonate with congenitally corrected transposition of the great arteries (Cc-TGA) and in a 10-month-old boy who sustained unexplained postoperative cardiac arrest.

Evaluation of vascular anastomoses/reconstructions. We used ICG/IOFA in 4 patients to assess the quality and patency of vascular anastomoses in 4 different clinical scenarios ${ }^{1}$ : left subclavianto-left common carotid artery as a part of complete repair of a vascular ring (right aortic arch with aberrant retroesophageal left subclavian artery and persistent Kommerell diverticulum), ${ }^{2}$ repair of aortic coarctation, ${ }^{3}$ repair of an interrupted aortic arch (Figure 2, C), and ${ }^{4}$ reconstructed pulmonary arterial branches in a 10-month-old girl with congenital pulmonary valve and bilateral branch pulmonary artery stenoses (Figure E1, $A$ and $B$ ). Assessment of myocardial perfusion. ICG/IOFA was used in cases where coronary arteries required reimplantation (arterial switch/ Ross) or manipulation (Norwood) (Figure E2, $A$ and $B$ ).

Thoracic duct localization. ICG/IOFA was used in a 3-week-old, $3.3-\mathrm{kg}$ neonate who underwent median sternotomy with repair of aortic coarctation and closure of a ventricular septal defect. She experienced a high output $(200 \mathrm{~mL} / \mathrm{d})$ right-sided chylothorax that failed to respond to conservative treatment. The decision was made to proceed to the operating room for right thoracotomy and thoracic duct ligation. ICG was injected subcutaneously $(0.9 \mathrm{~mL} / \mathrm{side})$ in both groins. The duct was readily localized and successfully ligated (Figure E3).

\section{RESULTS}

There were no perioperative mortalities or morbidities related to ICG or the technique used. We obtained $20 \mathrm{im}-$ ages from 15 patients. The technique was more beneficial in the assessment of myocardial perfusion; localization of epicardial coronary arteries, especially in reoperations where ventriculotomy is required; and evaluation of the patency of systemic-to-pulmonary artery shunts. Deeper structures, such as pulmonary arterial branches, are a bit challenging to visualize owing to their anatomic location and require special exposure techniques. Images of patent shunts and reconstructed vascular anastomoses closely correlated with intraoperative echocardiographic assessment and postoperative cross-sectional images (Figure 7).

We have experienced real value in 2 interesting clinical scenarios. The first scenario was the case of a 10-monthold boy who sustained unexplained cardiac arrest after uneventful repair of a double-chamber right ventricle. Intraoperatively, we visualized an anomalous LAD coronary artery from the right coronary artery (RCA) crossing the RVOT that was not diagnosed preoperatively. He was resuscitated and placed on extracorporeal membrane oxygenation (ECMO) support. On follow-up echocardiography, a large left ventricular thrombus was identified (probably related to sluggish flow through the heart and poor contractility). He was taken to the cardiac catheterization laboratory to evaluate the coronary arteries and rule out coronary thrombosis, but unfortunately, it was not possible to obtain satisfactory coronary images owing to poor myocardial ejection and the inability to discontinue ECMO to obtain satisfactory coronary images. The patient was taken to the operating room, where a left ventricular transapical approach was performed with evacuation of the thrombus. Intraoperative IOFA was then performed that confirmed widely patent coronary arteries (Figure E4) and the anomalous LAD origin from the RCA. The patient underwent heart transplantation due to lack of myocardial recovery. This avoided the challenging transfer of the patient for a computed tomography (CT) scan to obtain further images and avoided the risk of contrast-induced nephropathy.

The other interesting scenario was the case of a neonate with pulmonary atresia, heterotaxy, and infradiaphragmatic total anomalous pulmonary venous connection (TAPVC) who underwent repair of the obstructed TAPVC and a 


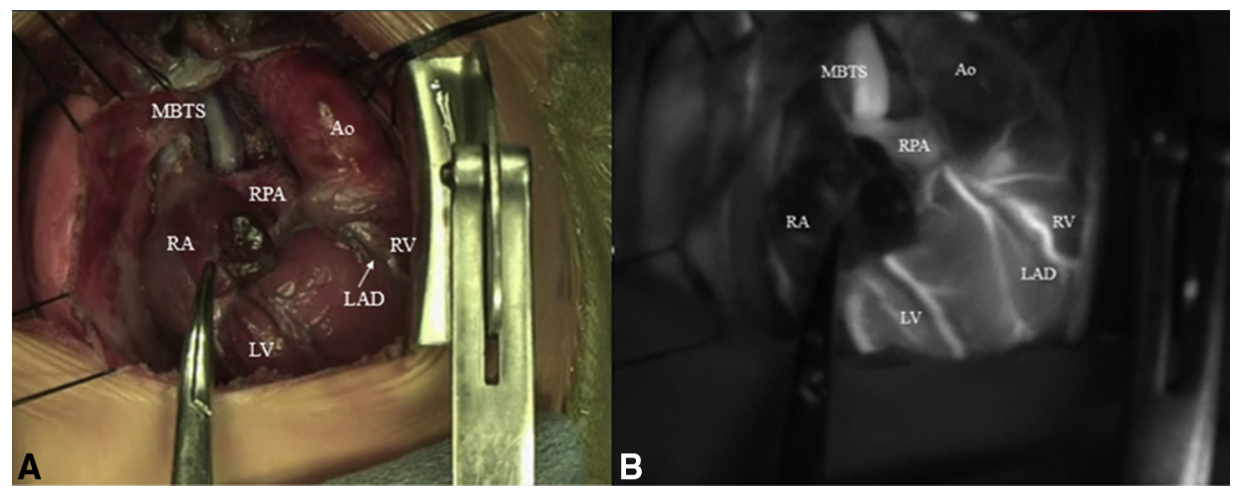

FIGURE 3. A neonate with double-outlet right ventricle, atrioventricular discordance, and pulmonary atresia who underwent a right modified BlalockTaussig shunt using a cryopreserved saphenous vein homograft. A, Intraoperative baseline photo showing the gross anatomy. B, Excellent visualization of the shunt with good flow of indocyanine green into both branch pulmonary arteries. Coronary arteries are also visualized. MBTS, Modified BlalockTaussig shunt; $A o$, aorta; $R P A$, right pulmonary artery; $R A$, right atrium; $R V$, right ventricle; $L A D$, left anterior descending coronary artery; $L V$, left ventricle.

placement of a central shunt with ligation of right sided major aortopulmonary collateral arteries (MAPCAs) based on the preoperative CT scan. The patient was not evaluated with cardiac catheterization as was planned preoperatively, owing to the need for emergency repair of the obstructed TAPVC. This was one of our earlier cases using this technology, and when we performed ICG intraoperatively, we could not obtain satisfactory images for the entire shunt owing to its position, and the patient had adequate oxygen saturation, so we assumed it was patent and that the inadequate images were related to our limited experience with the technique. The shunt patency was confirmed on postoperative echocardiography multiple times; however, the patient began to demonstrate desaturation and was taken for cardiac catheterization to evaluate the shunt, which revealed 2 additional left-sided MAPCAs that caused competitive flow in the shunt, resulting in its occlusion. We confirmed this in the operating room with ICG, and the MAPCAs were ligated with constructing a new shunt.

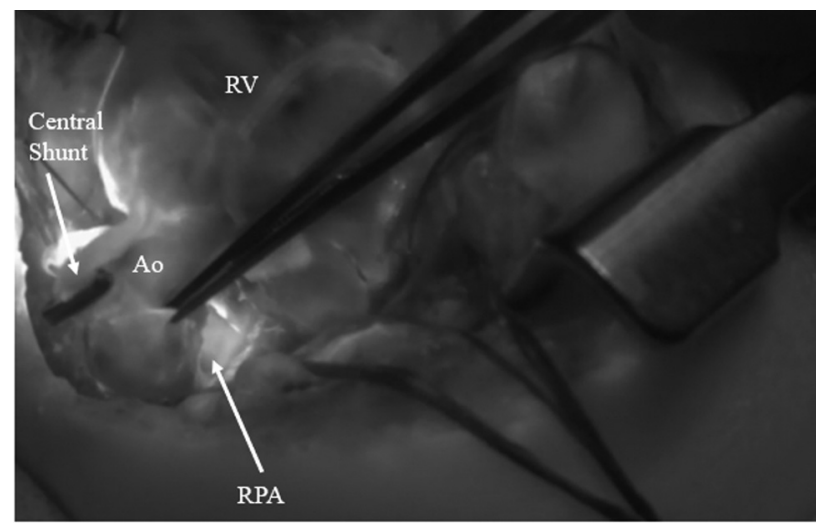

FIGURE 4. Intraoperative evaluation of a central aortopulmonary shunt in a neonate with pulmonary atresia. Note the good flow in the right main branch pulmonary artery. $A o$, Aorta; $R P A$, right pulmonary artery; $R V$, right ventricle.
Echocardiography was clearly misleading in this scenario. ICG/IOFA correlated well with cardiac catheterization.

The patient underwent right thoracotomy for ligation of the thoracic duct, and the duct was localized successfully and ligated. Postoperative chest tube output decreased significantly, and the tube was removed 72 hours later with institution of full breast feeding.

\section{DISCUSSION}

The evolution and safety profile of IOFA technology has led to its widespread use in a variety of specialties. The ability to perform rapid on-table assessment with good visualization is a major advantage of this technique. Other potential advantages include avoidance of potential harmful effects of contrast agents, no need for catheter manipulation, and the speed of assessment.

This was our first experience using this technology, and there are insufficient data in the literature regarding the technical accuracy or a real comparison between the images

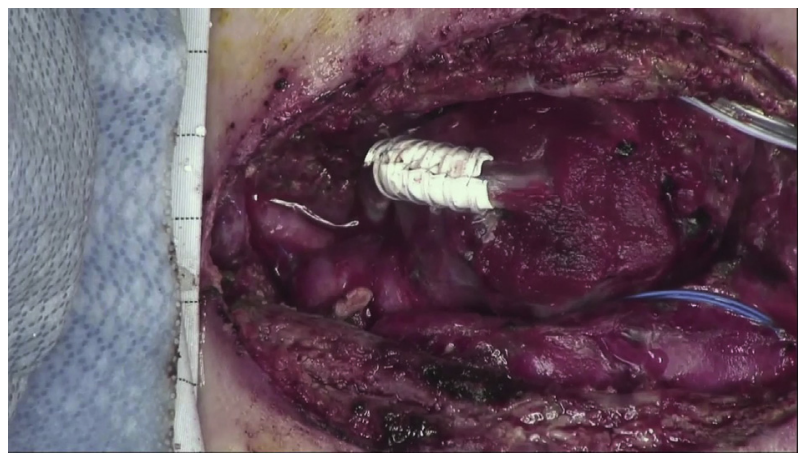

VIDEO 2. Good flow in the Sano shunt is seen in a neonate who underwent sutureless repair of pulmonary vein stenosis and implantation of a Sano shunt using a cryopreserved saphenous vein homograft due to concomitant pulmonary atresia. Video available at: https://www.jtcvs. org/article/S2666-2507(21)00178-4/fulltext. 


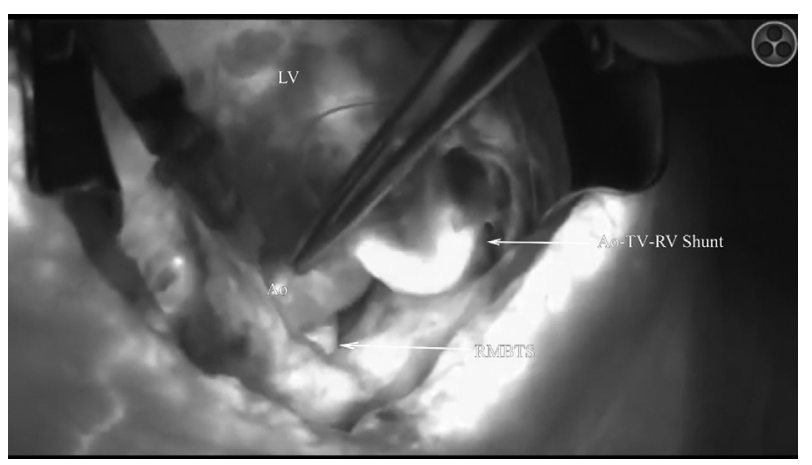

VIDEO 3. A double-shunt strategy using 2 cryopreserved saphenous vein homografts was used in this rare neonatal case of pulmonary atresia with intact septum and right ventricular-dependent coronary circulation. Shown is a right modified Blalock-Taussig shunt to improve pulmonary blood flow, and an aorto-tricuspid-right ventricular shunt to improve coronary blood flow. Ao, Aorta; $L V$, left ventricle; RMBTS, right modified Blalock-Taussig shunt; $A o-T V-R V$, aorto-tricuspid-right ventricular shunt. Video available at: https://www.jtcvs.org/article/S2666-2507(21)00178-4/ fulltext.

and data obtained by the current technology and other standard imaging modalities, such as angiography. Nonetheless, we believe that the technique can be used to evaluate and assess myocardial perfusion after coronary reimplantations and to evaluate the patency of systemic-to-pulmonary artery shunts after reconstruction. We have found the greatest technical accuracy in systemic-to-pulmonary artery shunt assessment, evaluation and assessment of coronary arteries and myocardial perfusion, and localization of epicardial coronary arteries during reoperations. It is excellent in thoracic duct localization and has low to intermediate accuracy in assessment of aortic arch augmentation/coarctation repair and assessment of large vessel reconstruction, such as pulmonary arterioplasty.

We found limitations in the assessment of deeper structures, such as pulmonary artery branch reconstruction, but we believe that this could be simply related to exposure challenges, especially in small infants and neonates or with small incisions.

Despite the wide use of ICG in other specialties, its application in cardiac surgery has been limited to assessment of coronary artery bypass graft patency. ${ }^{12}$ In the field of congenital heart surgery, data on its use and the various applications in which this technology can be useful are very limited. A study reported by Kogon and colleagues ${ }^{13}$ used ICG in 18 patients to assess operative repair in a variety of congenital cases, including systemic-to-pulmonary artery shunt, vascular anastomosis patency, and epicardial coronary artery localization. The authors concluded that this technology could be useful to decrease the need for postoperative intervention and its associated morbidities and mortalities. A recent multicenter review by Feins and

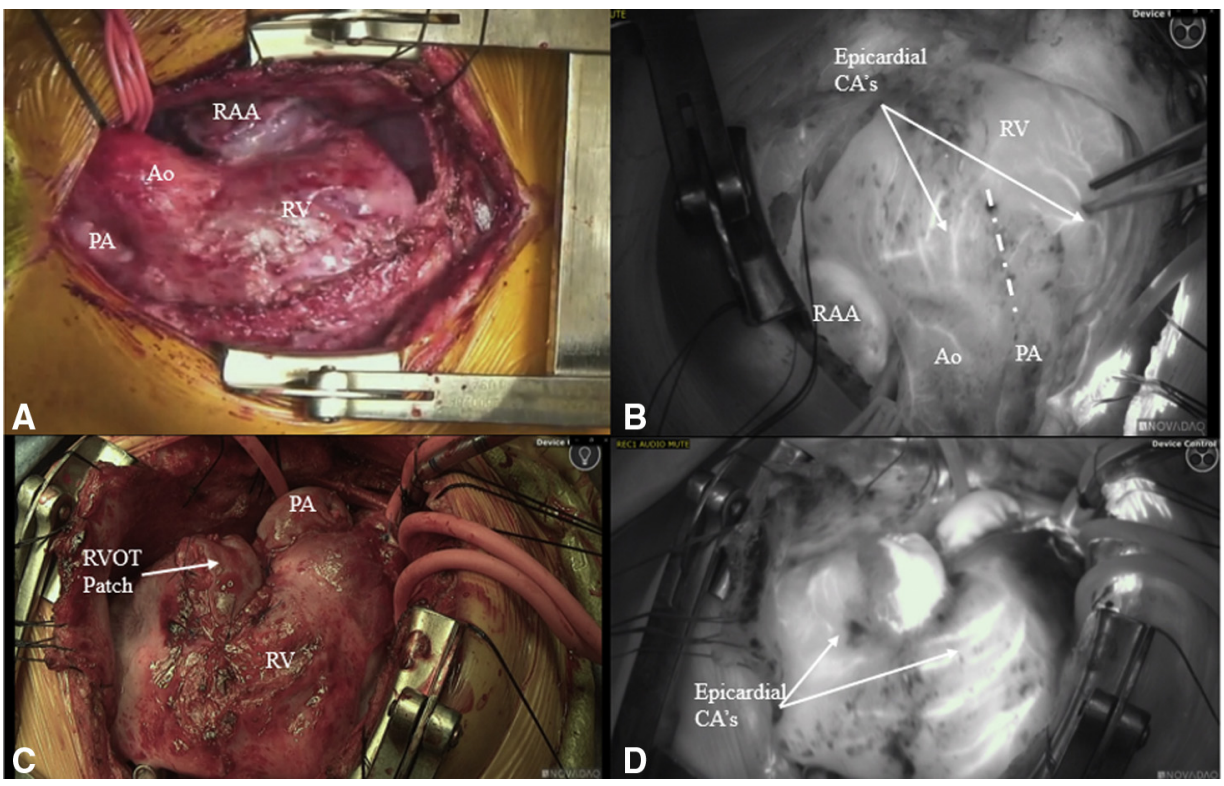

FIGURE 5. A patient who underwent repeat sternotomy for 2-ventricle repair of a double-outlet right ventricle, near pulmonary atresia, and abnormal atrial situs. He underwent an initial right modified Blalock-Taussig shunt as a neonate. A, After repeat sternotomy and adhesiolysis, it is clearly difficult to locate any epicardial coronary artery with any degree of accuracy and safety. B, Intraoperative fluorescence angiography showing the safe area for future ventriculotomy (white dotted line) in between 2 major epicardial coronary arteries. C, Main pulmonary artery and right ventricular infundibular patches were safely applied, sparing the native pulmonary valve. D, Repeat indocyanine green injection showing no compromise in any of the epicardial coronary arteries. $R A A$, Right atrial appendage; $A o$, aorta; $P A$, pulmonary artery; $R V$, right ventricle; $C A$, coronary artery; $R V O T$, right ventricular outflow tract. 


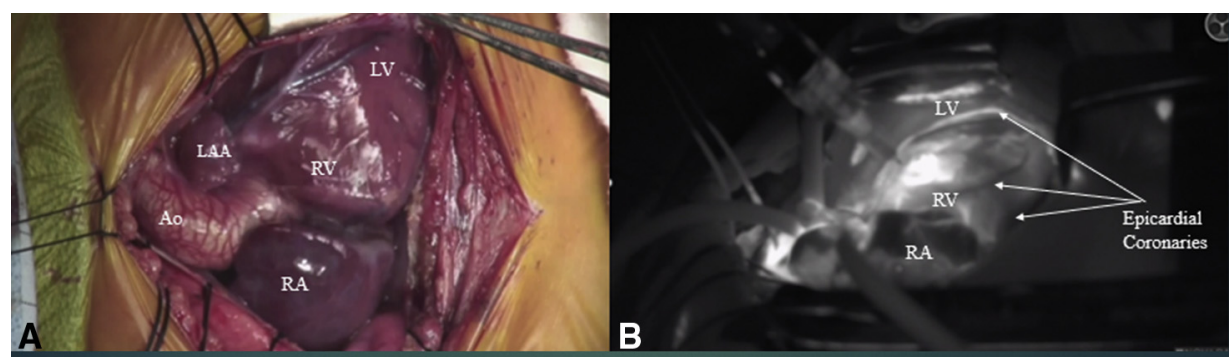

FIGURE 6. A, A rare neonatal case of pulmonary atresia with intact ventricular septum and right ventricle-dependent coronary circulation. B, Intraoperative visualization of several right ventricle-to-epicardial coronary artery communication via direct injection of indocyanine green into the right ventricle. This patient had bilateral coronary ostial atresia. $L V$, Left ventricle; $L A A$, left atrial appendage; $R V$, right ventricle; $A o$, aorta; $R A$, right atrium.

colleagues $^{14}$ reported the use of ICG angiography for intraoperative coronary artery imaging and operative planning. The authors described the technique in 21 patients who required complete repair via a ventriculotomy, with the goal of avoiding any injury to the epicardial coronary arteries during this process. Our study and findings support these 2 previous reports, and we have identified several other applications for this technology.

In reoperations, it is quite challenging to identify epicardial coronary arteries safely. This becomes of paramount importance in patients with unusual anatomy, such as Cc-TGA, ventricular inversion, and abnormal situs. The need for ventriculotomy for repair of intracardiac defects or conduit placement increases the risk of epicardial coronary artery injuries if they are not identified appropriately.
Preoperative cross-sectional imaging or angiography may detect the presence of an anomalous coronary artery course, but precise intraoperative localization of this anomalous course is critical. ICG has facilitated this goal and made it quite feasible.

When it comes to assessment of vascular anastomosis/ reconstruction, the image quality is good, but it may not have the same degree of usefulness as for other indications, but we feel that we can see the entire reconstructed/ augmented arch or the aortic end-to-end anastomosis without much difficulty. Flow can be visualized in the augmented vessel/reconstructed anastomosis, and the hand-held probe facilitates visualization in many cases. The challenges are mostly related to the augmented branch pulmonary arteries owing to challenges related to exposure.

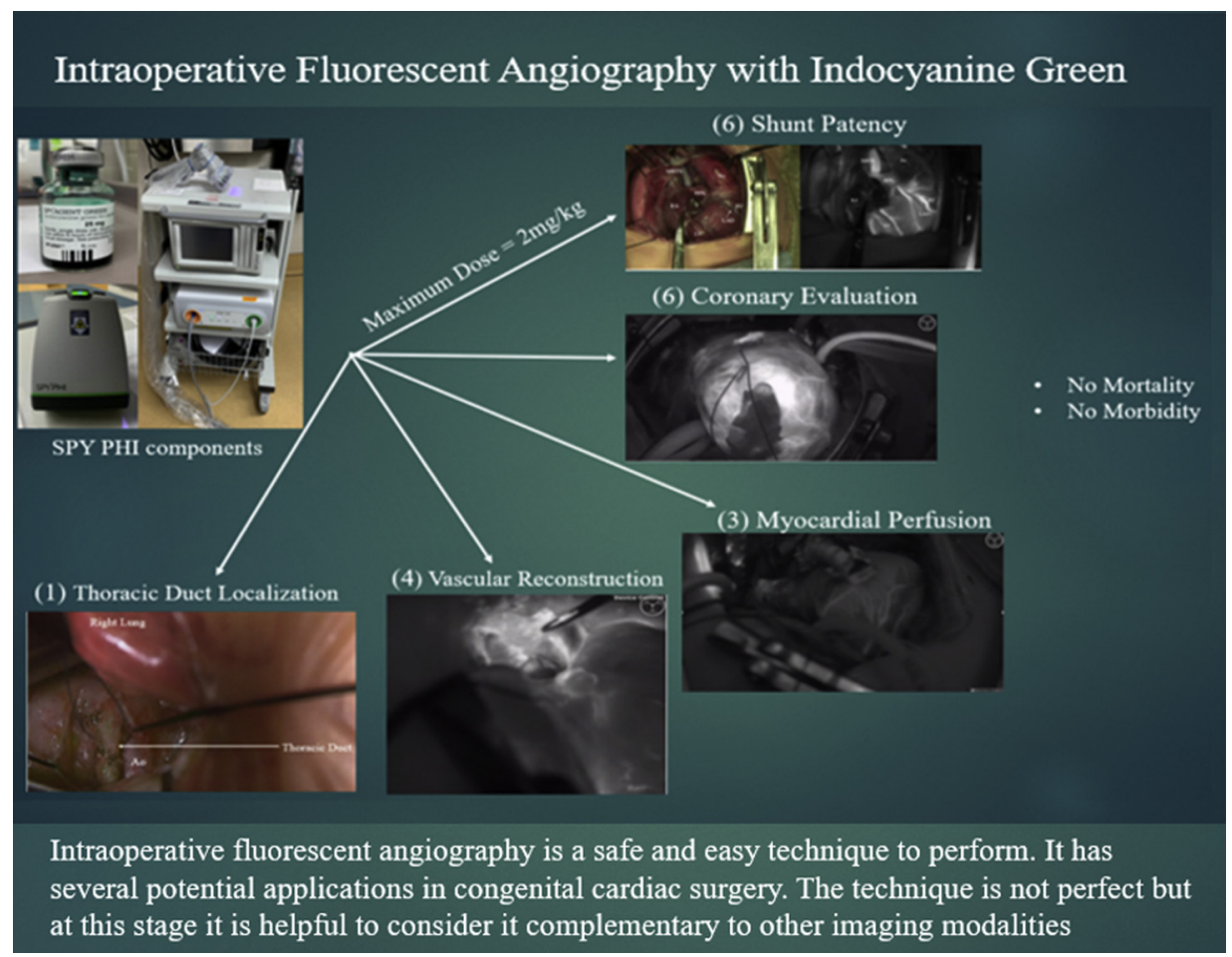

FIGURE 7. A summary of the different applications where we used intraoperative fluorescent angiography with indocyanine green and the results. 
In 1 case, we used a mini probe (as used in laparoscopic surgery) to enable us to navigate deeply in the chest.

Assessment of myocardial perfusion is important in all cases where the coronary arteries are being manipulated or reimplanted, such as with arterial switch, the Ross procedure, and the Norwood procedure, especially when the ascending aorta is quite hypoplastic. Any slight twisting or kinking in the coronary button or the Damus-Kay-Stansel anastomosis could result in significant hemodynamic alterations or even myocardial ischemia and cardiac arrest postoperatively. One may argue that these changes are not subtle and that the current technology may not add much, as will be clinically obvious in many of these scenarios if there is any coronary problem.

We used to perform mass ligation of the tissues between the aorta, the esophagus, and the spine and administer a high-fat diet (cream) before thoracic duct ligation to facilitate localization intraoperatively; however, the failure rate with the approach is not insignificant, and failure is related mostly to inaccurate localization of the thoracic duct and abnormal lymphatic anatomy. We find that ICG adds precision and helps identify the thoracic duct with greater degree of accuracy in this scenario.

\section{Limitations and Pitfalls of ICG}

We believe that this technique has a short learning curve, but we note several limitations. First, there is no standard or fixed dose for ICG for each specific indication, and although the ICG injection can be repeated safely, it is important to avoid spillage of the dye, which tends to stain tissues and may require waiting for it to wash out before repeating the injection, increasing the duration of the procedure and resulting in suboptimal images. Second, overdosing or underdosing can occur, either generating very bright images that obscure anatomic details or necessitating repeat injection to avoid misleading the surgeon. Third, there is poor penetration for deeper structures, such as pulmonary arteries which may require special techniques for exposure. Fourth, it is difficult to visualize synthetic grafts (expanded polytetrafluoroethylene [PTFE]) owing to poor penetration of the dye. However, we use solely cryopreserved saphenous vein homografts as our MBTS conduit of choice. This can be easily seen with this technology. For PTFE conduits, we do not believe the graft will be visualized, but the outflow to the pulmonary artery will be seen after ICG injection. This may not achieve the same degree of accuracy as in saphenous vein conduits and constitutes a limitation and potential for misinterpretation. Finally, in small neonates and minimally invasive exposure, using the standard hand-held probe can be difficult, and it may need to be replaced with a minimally invasive probe (as used during laparoscopic procedures) to obtain satisfactory images.

Our goal in the present study was to evaluate the use of this technique as a complementary evaluation along with intraoperative echocardiography and postoperative imaging modalities. We view the current technology in 2 different ways: replacement and confirmatory. As replacement technology, we can see the potential for this to replace some preoperative or postoperative routine imaging modalities. For example, if we are performing a preoperative CT scan to evaluate epicardial coronary anatomy in a reoperative setting, we can use the SPY PHI instead. The images of the epicardial coronary arteries are the best obtained so far, and this may minimize cost, avoid radiation, and prevent contrast-induced nephropathy especially before a long, complex reoperation. We can view it as a replacement for magnetic resonance imaging or conventional lymphangiography in some cases of chylothorax. As confirmatory technology, it confirms what we know in some cases-but will it reach the point at which we will completely rely on it? That remains to be determined with our future studies using this technology.

A remaining question is whether or not to make a revision based on the SPY images. For now, and until we gain more experience with this technology, we will use it as a complementary technique along with all other intraoperative clinical and echocardiographic data before revising any shunt and/or anastomosis.

\section{CONCLUSIONS}

We identified other potential applications for the ICG technology beyond coronary artery assessment. The technique is not perfect, but at this stage it is helpful to consider it as a complementary modality in addition to other available diagnostic modalities.

We believe that this report represents an addition to the literature of congenital heart surgery with IOFA; however, future studies are needed to compare this technology with other available diagnostic modalities.

\section{Conflict of Interest Statement}

Dr Said serves as a consultant for Cryolife. Drs Marey and Hiremath reported no conflicts of interest.

The Journal policy requires editors and reviewers to disclose conflicts of interest and to decline handling or reviewing manuscripts for which they may have a conflict of interest. The editors and reviewers of this article have no conflicts of interest.

The authors had full control of the study, methods used, assessment of images, and writing the manuscript. Outside assistance was only provided in relation to preparation of the ICG and intraoperative acquisition of the images.

We thank Mahmoud Said, Minnetonka High School, Minneapolis, Minn, for his assistance in editing several of the visual materials and figures provided for this study. We also thank Ms. Tanya Wessels, and Jeri Havens from Stryker for their valuable guidance 
in providing the proper dosage of indocyanine green and intraoperative assistance in obtaining the images.

\section{References}

1. Hol PK, Lingaas PS, Lundblad R, Rein KA, Vatne K, Smith HJ, et al. Intraoperative angiography leads to graft revision in coronary artery bypass surgery. Ann Thorac Surg. 2004;78:502-5; discussion 505.

2. Benson RC, Kues HA. Fluorescence properties of indocyanine green as related to angiography. Phys Med Biol. 1978;23:159-63.

3. Ryu G, Moon C, van Hemert J, Sagong M. Quantitative analysis of choroidal vasculature in polypoidal choroidal vasculopathy using ultra-widefield indocyanine green angiography. Sci Rep. 2020;10:18272.

4. Ushijima H, Kawamura J, Ueda K, Yane Y, Yoshioka Y, Daito K, et al. Visualization of lymphatic flow in laparoscopic colon cancer surgery using indocyanine green fluorescence imaging. Sci Rep. 2020;10:14274.

5. Ngô C, Sharifzadehgan S, Lecurieux-Lafayette C, Belhouari H, Rousseau D, Bonsang-Kitzis $\mathrm{H}$, et al. Indocyanine green for sentinel lymph node detection in early breast cancer: prospective evaluation of detection rate and toxicityThe FLUOBREAST trial. Breast J. 2020;26:2357-63.

6. Cherrick GR, Stein SW, Leevy CM, Davidson CS. Indocyanine green: observations on its physical properties, plasma decay, and hepatic extraction. J Clin Invest. 1960;39:592-600.

7. Yamamoto $\mathrm{M}$, Orihashi $\mathrm{K}$, Sato $\mathrm{T}$. Intraoperative indocyanine green imaging technique in cardiovascular surgery. IntechOpen (Online). 2013; Chapter 5:81-97.
8. Flower RW, Hochheimer BF. A clinical technique and apparatus for simultaneous angiography of the separate retinal and choroidal circulations. Invest Ophthalmol. 1973;12:248-61.

9. Kitai T, Inomoto T, Miwa M, Shikayama T. Fluorescence navigation with indocyanine green for detecting sentinel lymph nodes in breast cancer. Breast Cancer. 2005; 12:211-5.

10. Kinami S, Oonishi T, Fujita J, Tomita Y, Funaki H, Fujita H, et al. Optimal settings and accuracy of indocyanine green fluorescence imaging for sentinel node biopsy in early gastric cancer. Oncol Lett. 2016;11:4055-62.

11. Yamamoto M, Sasaguri S, Sato T. Assessing intraoperative blood flow in cardiovascular surgery. Surg Today. 2011;41:1467-74.

12. Handa T, Katare RG, Sasaguri S, Sato T. Preliminary experience for the evaluation of the intraoperative graft patency with real color charge-coupled device camera system: an advanced device for simultaneous capturing of color and near-infrared images during coronary artery bypass graft. Interact Cardiovasc Thorac Surg. 2009;9:150-4.

13. Kogon B, Fernandez J, Kanter K, Kirshbom P, Vincent B, Maher K, et al. The role of intraoperative indocyanine green fluorescence angiography in pediatric cardiac surgery. Ann Thorac Surg. 2009;88:632-6.

14. Feins EN, Si MS, Baird CW, Emani SM. Intraoperative coronary artery imaging for planning. Semin Thorac Cardiovasc Surg Pediatr Card Surg Annu. 2020;23: 11-6.

Key Words: indocyanine green, imaging technology, congenital heart surgery, fluorescence, SPYPHI 


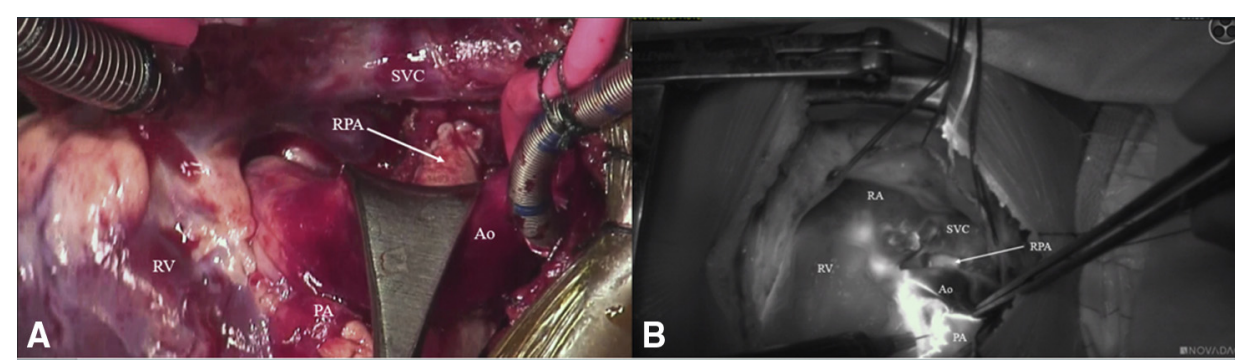

FIGURE E1. A, Operative photo demonstrating the augmented right main branch pulmonary artery with a pulmonary homograft patch. B, Correlated intraoperative fluorescent image. $S V C$, Superior vena cava; $R P A$, right main branch pulmonary artery; $A o$, aorta; $R A$, right atrium; $R V$, right ventricle; $P A$, main pulmonary artery.

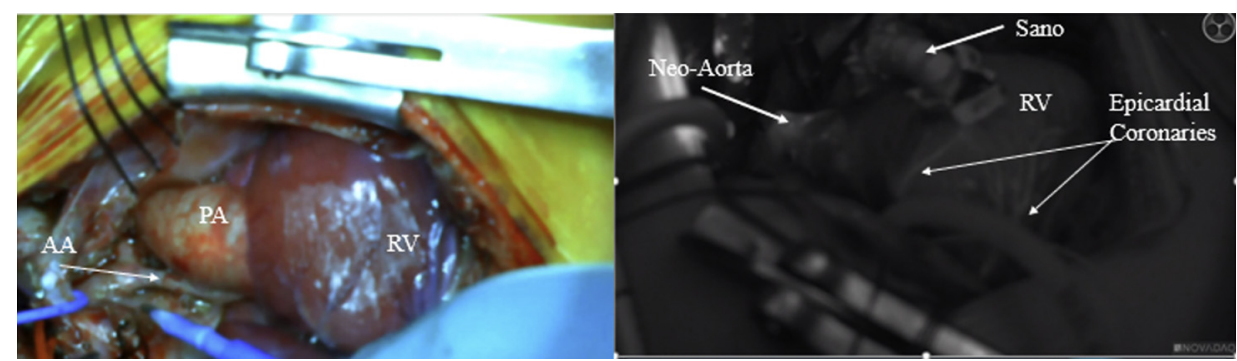

FIGURE E2. A, A neonate with aortic and mitral atresia who underwent a modified Norwood/Sano procedure. B, Good assessment of myocardial perfusion and epicardial coronary arteries with intraoperative fluorescence. Note the very small ascending aorta, which increases the risk of coronary obstruction during the neo-aorta reconstruction. $A A$, Ascending aorta; $P A$, pulmonary artery; $R V$, right ventricle. 


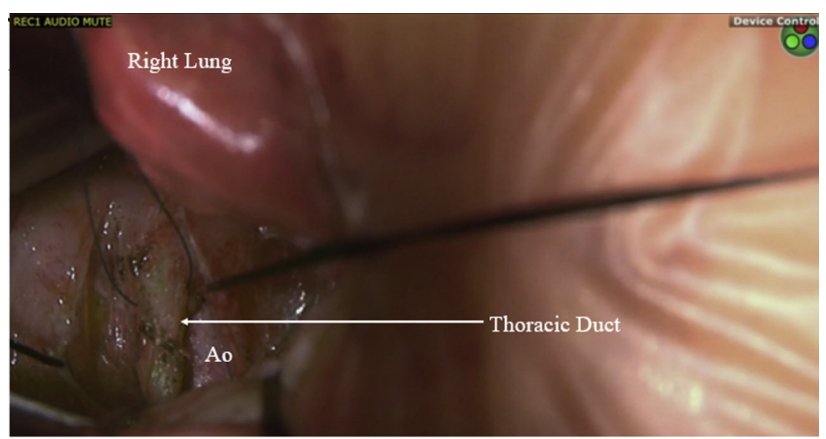

FIGURE E3. Localization of the thoracic duct via a right thoracotomy was easy after indocyanine green was injected in both groins subcutaneously in this neonate, who experienced a high-output chylothorax after aortic coarctation repair. Ao, Aorta.

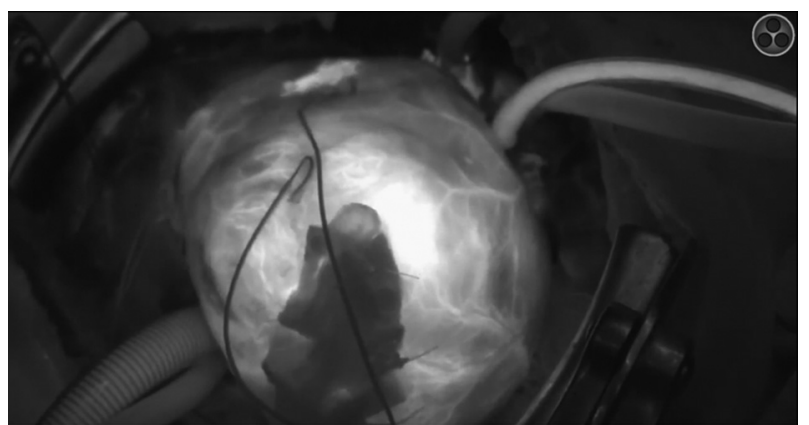

FIGURE E4. Complete visualization of all epicardial coronary arteries in a 10-month-old who suffered unexplained cardiac arrest, was placed on extracorporeal membrane oxygenation (ECMO) support, and developed a large left ventricular thrombus. The thrombus was evacuated via a left ventricular transapical approach. We could not visualize the coronary arteries with accuracy in the cardiac catheterization laboratory owing to poor myocardial ejection while on ECMO. 